\title{
Block of c-Fos and JunB Expression by Antisense Oligonucleotides Inhibits Light-induced Phase Shifts of the Mammalian Circadian Clock
}

\author{
F. Wollnik ${ }^{1}$, W. Brysch ${ }^{2}$, E. Uhlmann ${ }^{3}$, F. Gillardon ${ }^{4}$, R. Bravo ${ }^{5}$, M. Zimmermann ${ }^{4}$, K. H. Schlingensiepen ${ }^{6}$ and \\ T. Herdegen ${ }^{4}$ \\ ${ }^{1}$ Faculty of Biology, University of Konstanz, PO 5560, 78464 Konstanz, Germany \\ ²Biognostik Company, Carl-Giesecke Str. 3, 37079 Göttingen, Germany \\ ${ }^{3}$ Hoechst AG, 65926 Frankfurt, Germany \\ ${ }^{4}$ II Institute of Physiology, University of Heidelberg, Im Neuenheimer Feld 326, 69120 Heidelberg, Germany \\ ${ }^{5}$ Bristol-Myers Squibb Pharmaceutical Research Institute, Department of Molecular Biology, PO 4000, Princeton, NJ 08543, USA \\ ${ }^{6}$ Laboratory of Molecular Neuro- and Tumor Biology, Max-Planck-Institute for Biophysical Chemistry, Am Fassberg 11, 37077 \\ Göttingen, Germany
}

Key words: C-Jun, FosB, immediate-early gene, rat, suprachiasmatic nucleus, inducible transcription factor

\begin{abstract}
Light-induced phase shifts of circadian rhythmic locomotor activity are associated with the expression of c-Jun, JunB, c-Fos and FosB transcription factors in the rat suprachiasmatic nucleus, as shown in the present study. In order to explore the importance of c-Fos and JunB, the predominantly expressed AP-1 proteins for the phaseshifting effects of light, we blocked the expression of c-Fos and JunB in the suprachiasmatic nucleus of male rats, housed under constant darkness, by intracerebroventricular application of $2 \mu \mathrm{l}$ of $1 \mathrm{mM}$ antisense phosphorothioate oligodeoxynucleotides (ASO) specifically directed against c-fos and junB mRNA. A light pulse (300 lux for $1 \mathrm{~h}$ ) at circadian time 15 induced a significant phase shift (by $125 \pm 15 \mathrm{~min}$ ) of the circadian locomotor activity rhythm, whereas application of ASO $6 \mathrm{~h}$ before the light pulse completely prevented this phase shift. Application of control nonsense oligodeoxynucleotides had no effect. ASO strongly reduced the light-induced expression of c-Fos and JunB proteins. In contrast, light pulses with or without the control nonsense oligodeoxynucleotides evoked strong nuclear c-Fos and JunB immunoreactivity in the rat suprachiasmatic nucleus. These results demonstrate for the first time that inducible transcription factors such as c-Fos and JunB are an essential part of fundamental biological processes in the adult mammalian nervous system, e.g. of light-induced phase shifts of the circadian pacemaker.
\end{abstract}

\section{Introduction}

The suprachiasmatic nucleus ( $\mathrm{SCN}$ ) is the predominant circadian pacemaker in mammals regulating a variety of basic physiological and behavioural rhythms (reviewed by Wollnik, 1992; Takahashi, 1993). The daily light-dark cycle synchronizes the endogenous circadian pacemaker within the SCN to the environmental $24 \mathrm{~h}$ rhythm. However, the molecular genetic mechanisms by which light entrains the circadian clock are poorly understood.

Previous studies have demonstrated that light-induced phase shifts of circadian rhythms induce immediate-early genes such as c-jun, junB, c-fos and NGFI-A (synonyms of NGFI-A are Krox-24, Zif/268, Egr-I) mRNAs in rodent SCN neurons (Rea, 1989; Aronin et al., 1990; Earnest et al., 1990; Kornhauser et al., 1990, 1992; Rusak et al., 1990; Ebling et al., 1991; Sutin and Kilduff, 1992; Chambille et al., 1993). These genes code for inducible transcription factors that bind to specific DNA elements regulating the transcription of their target genes (Ryseck and Bravo, 1991). Therefore, selective upregulation of inducible transcription factors orchestrates the reactive alterations in the cellular programme according to the physiological or pathological context of events (Bravo, 1990; Morgan and Curran, 1991). For example, the selective inhibition of $c-J u n, J u n B$ and JunD proteins specifically affects cellular proliferation and neuron differentiation (Kovary and Bravo, 1992; Schlingensiepen and Brysch, 1992; Schlingensiepen et al., 1993, 1994).

The following findings suggest the importance of inducible transcription factors for the function of the circadian pacemaker. (i) Inducible transcription factors are expressed in the SCN only during that circadian time when light is capable of shifting the circadian rhythm (reviewed by Takahashi, 1993). (ii) Expression of inducible transcription factors is mainly restricted to the ventrolateral part of the SCN, the terminal region of retinal afferents. (iii) The onset of 
circadian gating of inducible transcription factor induction is precisely correlated with the phase-shifting effects of the light (Kornhauser et al., 1990; Mead et al., 1992). Here we provide direct evidence that the light-induced shifts of circadian locomotor activity depend on the expression of the JunB and c-Fos proteins.

\section{Material and methods}

Adult male rats $(n=12)$ were stereotaxically implanted under anaesthesia $(100 \mathrm{mg} / \mathrm{kg}$ ketamine hydrochloride and $10 \mathrm{mg}$ xylazine, i.m.) with a microinjection guide-cannula targeted to the bottom of the third ventricle at the level of the ventral SCN. After 2 weeks, the rats were placed in individual cages equipped with a running wheel and were housed under constant dark conditions for 16 weeks. Wheelrunning activity was monitored on-line with a microcomputer system as described previously (Wollnik, 1991).

Every 4 weeks, the rats were subjected to one of the following treatments: (i) light pulse (300 lux, $1 \mathrm{~h}$ ) at circadian time (CT) 15 , when light pulses induce a maximal phase delay of circadian activity rhythms; (ii) intracerebroventricular (i.c.v.) application of antisense phosphorothioate oligodeoxynucleotides (ASO; 1:1 mixture of c-fos and $j u n B$ ASO, each $1 \mathrm{mM}$ in $2 \mu \mathrm{l}$ physiological saline) at CT 9 alone or (iii) followed by a light pulse at CT 15; (iv) application of control nonsense oligonucleotides (NSO; 1:1 mixture of c-fos and junB ASO, each $1 \mathrm{mM}$ in $2 \mu$ l physiological saline) at CT 9 followed by a light pulse at CT 15 . Rats were reanaesthetized and killed $2-6 \mathrm{~h}$ after one of these treatments by transcardial perfusion with $4 \%$ paraformaldehyde. Following postfixation the brains were cryoprotected in $30 \%$ sucrose. Synthesis, stabilization protocol and proof of specificity of the phosphorothioate oligodeoxynucleotides complementary to the translation initiation site of junB and c-fos mRNA respectively and of the NSO were recently described in detail (Schlingensiepen et al., 1993; Gillardon et al., 1994). Briefly, the sequences of the c-fos ASO and the random c-fos NSO were CGA GAA CAT CAT GGT CGA AG and CCC TTA TTT ACT ACT TTC GC respectively; the NSO had some complementarity with the 5' end of the c-fos mRNA. The sequences of the junB ASO and mismatch junB NSO were TTT CGT GCA CAT CC and GTC CCT ATA CGA AC respectively (Biognostik, Göttingen, Germany; batch S-2044). The mismatch control sequence of the junB NSO contains the same CG content as the anti-junB sequence. This is important since an identical $C G$ content is required to achieve the same binding energy to a complementary sequence.

Phase shifts in the activity rhythm were determined by measuring the phase difference between eye-fitted lines connecting the onset of activity for a 14 day period before and after an experimental manipulation (according to Daan and Pittendrigh, 1976). Differences between experimental groups were evaluated by a univariate oneway analysis of variance (Statistica, StatSoft, Tulsa, USA). Sheffé's multiple $t$-test was used for comparison of individual means.

Serial cryostat cut sections $(35 \mu \mathrm{m})$ were immunocytochemically processed as free-floating sections and staining was visualized by the conventional avidin-biotin complex protocol (Herdegen et al., 1991). The primary polyclonal antisera against c-Jun (1:30 000), JunB (1:4000), c-Fos (1:25 000) and FosB (1:2000) proteins were incubated for $48 \mathrm{~h}$. The specificity of the antisera has been described in detail previously (Kovary and Bravo, 1991).

\section{Results}

Rats exposed to the light pulse for $1 \mathrm{~h}$ at CT 15 showed a robust phase shift of the circadian rhythm of wheel-running activity by

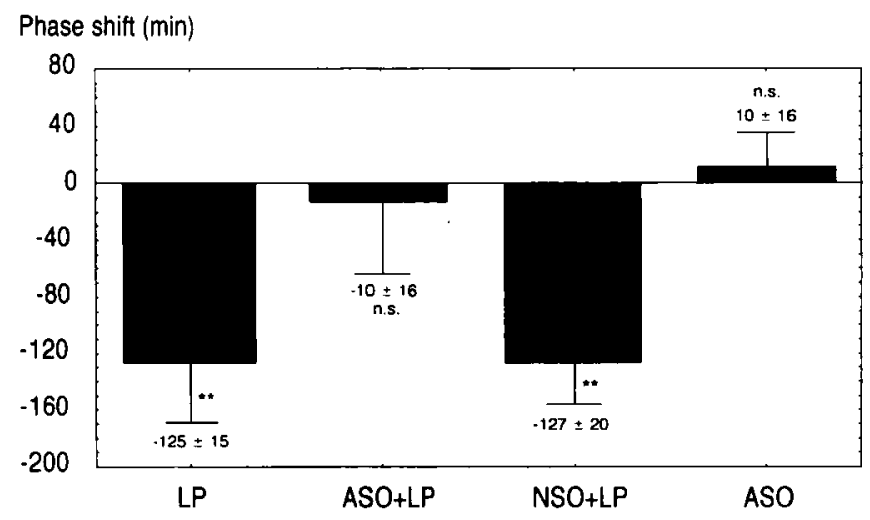

FIG. 1. Mean $( \pm S D$ ) of the phase shift of the circadian activity rhythm following application of a $1 \mathrm{~h}$ light pulse (LP, $n=9$ ), LP preceded by ASO $(n=11)$ or NSO $(n=2)$, and ASO alone $(n=3) . * * P<0.0001 ; n$. ., nonsignificant phase shift compared to the free-running endogenous rhythm.

$-125 \pm 15$ min that was almost identical to the phase shift induced by the i.c.v. application of NSO at CT 9 followed by light at CT 15 (phase shift $=-127 \pm 20 \mathrm{~min}$ ) (Fig. 1). In contrast, i.c.v. application of anti-c-fos and anti-junB ASO $6 \mathrm{~h}$ prior to the light pulse at CT 15 completely blocked the phase shift $(-10 \pm 16 \mathrm{~min})$. Injection of ASO without a subsequent light pulse neither changed the freerunning circadian rhythm nor shifted the locomotor activity (phase shift $=+10 \pm 16 \mathrm{~min}$ ). Figure $2 \mathrm{~A}$ shows representative activity records. In all animals, the injections of ASO or NSO did not alter the endogenous free-running circadian rhythms.

A light pulse at CT 15 alone or following application of NSO at CT 9 induced distinct nuclear immunoreactivity for c-Jun, JunB, cFos and FosB in the ventral SCN that persisted at least for $6 \mathrm{~h}$ (Figs 2B-D and 3). The numbers of c-Fos- and JunB- immunoreactive nuclei were strongly reduced by $\sim 40-65 \%$ and the intensity of labelling was substantially lowered when application of ASO preceded the light pulse (Fig. 2B, C) whereas expression of c-Jun and FosB was not affected (Fig. 2D). Application of ASO alone did not induce inducible transcription factors.

\section{Discussion}

Here we present findings about physiological effects of the inducible transcription factors $\mathrm{c}$-Fos and JunB in the adult mammalian nervous system in vivo. Block of expression of c-Fos and JunB by ASO prevented the light-induced phase shift of the circadian activity rhythms driven by molecular genetic changes in the SCN and strongly reduced the immunoreactivities of c-Fos and JunB. This block in phase shift was due to selective inhibition of c-Fos and JunB expression, because ASO alone did not interfere with the free-running rhythms, and NSO altered neither the effect of the light pulse nor the immunoreactivities. Thus, inducible transcription factors exert an important role in the adaptive synchronization of the endogenous clock to the environmental zeitgeber formed by the dark-light cycle. In addition, we have shown that light-induced phase shifts also induce, but to a lower degree, the expression of c-Jun and FosB proteins.

Nuclease-resistant phosphothioate oligodeoxynucleotides allow the selective inhibition of the synthesis of individual proteins (Neckers et al., 1992), and the ensuing loss of function permits conclusions on the physiological function of the missing protein (Nishikura and Murray, 1987; Gerdes et al., 1992; Kovary and Bravo, 1992). Recently, 

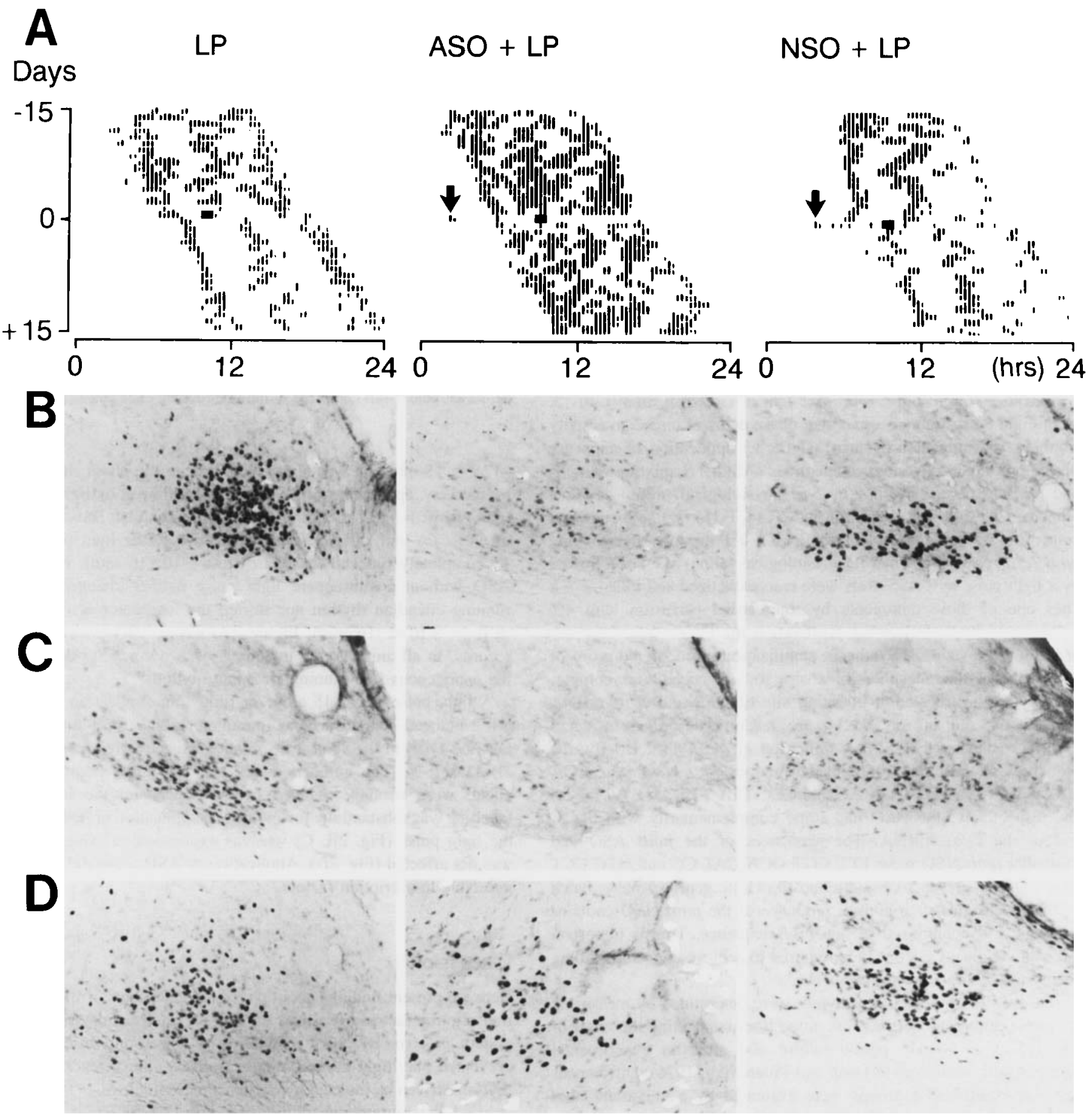

FIG. 2. (A) Representative recordings of wheel-running activity illustrating the phase shifts following a $1 \mathrm{~h}$ light pulse at CT 15 (LP, black rectangles), LP preceded by i.c.v. application of ASO at CT 9 (arrow) and LP preceded by i.c.v. application of NSO (arrow). Each line depicts a single 24 h period, and successive days are plotted from top to bottom. The recordings give the running activity between 15 days before $(+15)$ and 15 days after $(-15)$ the experimental treatment. Corresponding expression of (B) c-Fos, (C) JunB and (D) c-Jun in the SCN $4 \mathrm{~h}$ after LP (left column), ASO + LP (middle column) and NSO + LP (right column). Magnification (B-D), 400×.

it was demonstrated that the ASO used in the present study selectively prevents translation of JunB in hippocampal neurons in vitro (Schlingensiepen et al., 1993) and of c-Fos in spinal cord neurons in vivo (Gillardon et al., 1994). Function assays have conclusively demonstrated that reduced levels of c-Jun or JunB proteins induced by specific ASO selectively alter the differentiation or growth of hippocampal neurons (Schlingensiepen and Brysch, 1992; Schlingensiepen et al., 1993, 1994).

We applied ASO analogues complementary to junB and c-fos mRNA because previous data (Rusak et al., 1990, 1992; reviewed by Takahashi, 1993) and our results have shown that their protein products are the predominantly expressed proteins of the AP-1 family. 

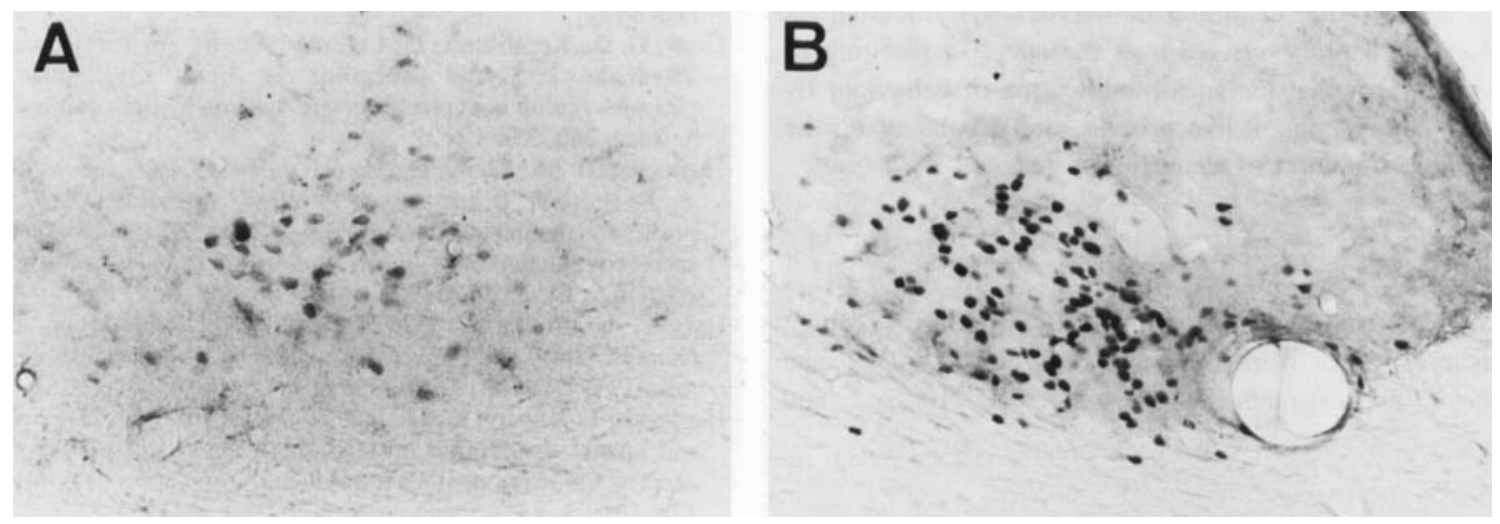

Fig. 3. (A) Basal expression of FosB in the SCN at CT 17. The rats were kept for 4 weeks in constant darkness. (B) Application of a $1 \mathrm{~h}$ light pulse at CT 15 increases the expression of FosB. Magnification, $400 \times$.

Furthermore, since light pulses also induce other AP-1 binding proteins such as c-Jun and FosB, these might compensate for the absence of only one transcription factor. Knock-out mice carrying a null-mutation of c-fos or c-jun show apparently no alterations in the embryonic and neonatal phenotype of the nervous system (Hilberg et al., 1993; Wang et al., 1992). Therefore, we decided to block the expression of both c-Fos and JunB, because these proteins are supposed to exert the main inducible transcription activity of AP-1 proteins in vitro (Kovary and Bravo, 1991) and in vivo following light pulse (Kornhauser et al., 1992) and other trans-synaptic excitation paradigms such as noxious cutaneous stimulation, epileptic seizures and cortical spreading depression (Herdegen et al., 1991, 1993b, 1994; Demmer et al., 1993; Gass et al., 1993). Therefore, cocktails containing two or more ASO against inducible transcription factors offer a good strategy to determine significant effects of the presumably dominant dimers and/or combinations of transcription factors.

Synthetic oligodeoxynucleotides can interact with biological systems, via non-specific associations with DNA, RNA and proteins. Oligodeoxynucleotides also exhibit the potency to block or even to strip membrane receptors. In general, these compounds can interfere with signalling pathways on various levels of synaptic-nuclear information transfer. The present study contains two internal controls that argue against non-specific actions of the applied synthesized oligodeoxynucleotides: (i) the investigation of several related proteins, and (ii) the computer-assisted monitoring of behaviour, i.e. circadian locomotor activity. Also, (i) ASO selectively reduce the expression of c-Fos and JunB but not that of c-Jun and FosB. Such an expression pattern of AP-1 proteins has not been observed so far. Numerous experimental paradigms for trans-synaptic stimulation of neurons evoke parallel induction of fos and jun mRNAs and proteins (Saffen et al., 1988; Sonnenberg et al., 1989; Cole et al., 1990; Wisden et al., 1990; Herdegen et al., 1991, 1993b; Gass et al., 1993), and this is also true for Fos and Jun expression in the SCN following light pulses (Rusak et al., 1990, 1992; Kornhauser et al., 1992). In contrast, selective up-regulation of c-Jun and JunD without Fos proteins is a general feature of the cell body response following axotomy (Herdegen et al., 1993a). (ii) Neither application of ASO or NSO alone nor the preceding application of light pulses interfered with the rhythm of locomotor activity. Circadian locomotor activity also depends on de novo protein synthesis (Takahashi and Turek, 1987; Wollnik et al., 1989), and the non-specific activation or inhibition of intraneuron signalling pathways affecting protein synthesis should result in dissociation of the monitored rhythmic activity. Our results clearly demonstrate robust circadian behaviour (i) that is shifted but does not disintegrate following the common application of both control NSO with subsequent light pulses, and (ii) that maintains its stability following application ASO or NSO alone.

The latency between application of ASO and light pulses also offers the possibility that other immediate-early genes are rapidly induced or that pre-existing transcription factors such as $\mathrm{Sp}-1$ are post-translationally activated in a sequence-independent manner (Perez et al., 1994). However, it is rather unlikely that these mechanisms mimic the specific alterations in inducible transcription factor expression and in locomotor activity.

The reduction of c-Fos and JunB levels affects several transcriptionally operating systems since Jun/Fos proteins bind to AP-1, CRE/ $\mathrm{CaRE}$ consensus sequences that are present in the promoters of many genes (Rauscher et al., 1988; Ivaskiv et al., 1990; Ryseck and Bravo, 1991). Moreover, these proteins dimerize with members of different transcription factor families, i.e. CRE-BP and ATF proteins (Hai and Curran, 1991; Masquilier and Sassone-Corsi, 1992; Hagmeyer et al., 1993), ligand-dependent transcription factors (Zhang et al., 1991; König et al., 1992) or liver-regenerating factor 1 (Hsu et al., 1992).

The expression of inducible transcription factors in the SCN by light are in the centre of a complex sequence of neurogenetic processes that starts with the excitation of SCN neurons by excitatory amino acid input via the retinohypothalamic tract (Kim and Dudek, 1991; Vindlacheruvu et al., 1992), activation of second messengers with subsequent phosphorylation of the CREB transcription factor (Ginty et al., 1993), and terminal expression of inducible transcription factors (Rusak et al., 1990, 1992; Kornhauser et al., 1992; Sutin and Kilduff, 1992). The target genes that are finally responsible for the shifted locomotor activity rhythm have still to be elucidated. While inducible transcription factors are involved in the adaptive synchronization of environmental stimuli, the genetic constituents of the mammalian circadian clock that drives the truly endogenous and self-sustained pacemaker are not yet known.

During the past decade, the importance of inducible transcription factors such as c-Fos and c-Jun in basic biological processes such as cell growth, mitosis and differentiation has been shown at the singlecell level and has founded a new area in biology (Curran et al., 1984; Ryseck et al., 1987; Almendral et al., 1988). Recently it was shown by the application of antisense against c-Fos in vivo that inducible transcription factors such as c-Fos play a functional role in behaviour, i.e. anxiety and pharmacologically modulated locomotion (Chiasson et al., 1992; Dragunow et al., 1993; Möller et al., 1994). Here 
we show that in the adult mammalian nervous system complex physiological and vital processes, such as the adaptive resetting of the circadian pacemaker that includes modification of behaviour by formation of a memory engram-like process, are dependent on the activity of inducible Jun and Fos transcription factors.

\section{Acknowledgements}

We thank Mrs Rita Hellmann and Mrs Tina Stroh for excellent technical assistance. This work was supported by the Deutsche Forschungsgemeinschaft (grants Wo 354/3-3, Zi 110/22-2 and Gr 650/5-2).

\section{Abbreviations}

ASO

CT antisense oligodeoxynucleotide

i.c.v. circadian time

NSO intracerebroventricular

SCN nonsense oligodeoxynucleotide suprachiasmatic nucleus

\section{References}

Almendral, J. M., Sommer, D., MacDonald-Bravo, H., Burckhardt, J., Perera, J. and Bravo, R. (1988) Complexity of the early genetic response to growth factors in mouse fibroblasts. Mol. Cell. Biol., 8, 2140-2148.

Aronin, N., Sagar, S. M., Sharp, F. R. and Schwartz, W. J. (1990) Light regulates expression of a fos-related protein in rat suprachiasmatic nucleus. Proc. Natl Acad. Sci. USA, 87, 5959-5962.

Bravo, R. (1990) Growth factor inducible genes in fibroblasts. In Habenicht, A. (ed.), Growth Factors, Differentiation Factors and Cytokines. SpringerVerlag, Berlin, pp. 324-343.

Chambille, I., Doyle, S. and Serviere, J. (1993) Photic induction and circadian expression of Fos-like protein. Immunohistochemical study in the retina and suprachiasmatic nuclei of hamster. Brain Res., 612, 138-150.

Chiasson, B., Hooper, M., Murphy, P. and Robertson, H. A. (1992) Antisense oligonucleotide eliminates in vivo expression of c-fos in mammalian brain. Eur. J. Pharmacol., 227, 451-452.

Cole, A. J., Abu-Shakra, S., Saffen, D. W., Baraban, J. M. and Worley, P. F. (1990) Rapid rise in transcription factor mRNAs in rat brain after electroshock-induced seizures. J. Neurochem., 55, 1920-1927.

Curran, T., Miller, A. D., Zokas, L. and Verma, I. M. (1984) Viral and cellular Fos proteins: a comparative analysis. Cell, 36, 259-268.

Daan, S. and Pittendrigh, C. S. (1976) A functional analysis of circadian pacemakers in nocturnal rodents. II. The variability of phase response curves. J. Comp. Physiol. A, 106, 253-266.

Demmer, J., Dragunow, M., Lawlor, P. A., Mason, S. E., Leah, J. D., Abraham, W. C. and Tate, W. P. (1993) Differential expression of immediate early genes after hippocampal long-term potentiation in awake rats. Mol. Brain Res., 17, 279-286.

Dragunow, M., Lawlor, P., Chiasson, B. and Robertson, H. A. (1993) cfos antisense generates apomorphine and amphetamine-induced rotation. NeuroReport, 5, 305-309.

Earnest, D. J., Iadarola, M., Yeh, H. H. and Olschowska, J. A. (1990) Photic regulation of $\mathrm{c}$-fos expression in neural components governing the entrainment of circadian rhythms. Exp. Neurol., 109, 353-361.

Ebling, F. J. P., Maywood, E. S., Staley, K., Humby, T., Hancock, D. C., Waters, C. M., Evant, G. I. and Hastings, M. H. (1991) The role of $\mathrm{N}$-methyl-D-aspartate-type glutamatergic neurotransmission in the photic induction of immediate-early gene expression in the suprachiasmatic nuclei of the Syrian hamster. J. Neuroendocrinol., 3, 641-652.

Gass, P., Herdegen, T., Bravo, R. and Kiessling, M. (1993) Induction of six immediate-early gene encoded proteins in the rat brain after kainic acid induced limbic seizures: effects of NMDA receptor antagonist MK-801. Eur. J. Neurosci., 5, 933-943.

Gerdes, W., Brysch, W., Schlingensiepen, K. H. and Seifert, W. (1992) Antisense bFGF oligodeoxynucleotides inhibit DNA synthesis of rat astrocytes. NeuroReport, 3, 43-46.

Gillardon, F., Beck, H., Uhlmann, E., Herdegen, T., Sandkühler, J. and Zimmermann, M. (1994) Inhibition of c-Fos protein expression in rat spinal cord by antisense oligodeoxynucleotide superfusion. Eur. J. Neurosci., 6,
$880-884$.

Ginty, D. D., Kornhauser, J. M., Thompson, M. A., Bading, H., Mayo, K. E., Takahashi, J. S. and Greenberg, M. E. (1993) Regulation of CREB phosphorylation in suprachiasmatic nucleus by light and a circadian clock. Science, 260, 238-241.

Hagmeyer, B. M., König, H., Herr, I., Offringa, R., Zantema, A., van der Eb, A. J., Herrlich, P. and Angel, P. (1993) Adenovirus E1A negatively and positively modulates transcription of AP-1 dependent genes by dimerspecific regulation of the DNA binding and transactivation activities of Jun. EMBO J., 12, 3559-3572.

Hai, T. and Curran, T. (1991) Cross-family dimerization of transcription factors Fos/Jun and ATF/CREB alters DNA binding specificity. Proc. Natl Acad. Sci. USA, 88, 3720-3724.

Herdegen, T., Kovary, K., Leah, J. D. and Bravo, R. (1991) Specific temporal and spatial distribution of JUN, FOS and KROX-24 proteins in spinal neurons following noxious transynaptic stimulation. J. Comp. Neurol.. 313, 178-191.

Herdegen, T., Brecht, S., Mayer, W., Leah, J. D., Kummer, W., Bravo, R. and Zimmermann, M. (1993a) Long-lasting expression of JUN and KROX transcription factors and nitric oxide synthase in intrinsic neurons of the rat brain following axotomy. J. Neurosci, 13, 4130-4145.

Herdegen, T., Sandkuihler, J., Gass, P., Kiessling, M., Bravo, R. and Zimmermann, M. (1993b) JUN, FOS, KROX and CREB transcription factor proteins in the rat cortex: basal expression and induction by spreading depression and epileptic seizures. J. Comp. Neurol., 333, 271-288.

Herdegen, T., Rüdiger, S., Mayer, B., Bravo, R. and Zimmermann, M. (1994) Expression of nitric oxide synthase and colocalisation with Jun, Fos and Krox transcription factors in spinal cord neurons following noxious stimulation of the rat hindpaw. Mol. Brain Res., 22, 245-258.

Hilberg, F., Agguzi, A.. Howells, N. and Wagner, E. F. (1993) c-Jun is essential for normal mouse development and hepatogenesis. Nature, 365, $179-181$

Hsu, J. C., Bravo, R. and Traub, R. (1992) Interaction among LRF-1, Jun B, c-Jun, and c-Fos define a regulatory network in the Gl phase of liver regeneration. Mol. Cell. Biol., 12, 4654-4665.

Ivaskiv, L. B., Liou, H. C., Kara, C. J., Lamph, W. W., Verma, I. and Glimcher, L. H. (1990) mXBP/CRE-BP2 and c-Jun form a complex which binds to the cyclic AMP, but not to the 12-O-tetracanoylphorbol-13-acetate response element. Mol. Cell. Biol., 10, 1609-1621.

Kim, Y. I. and Dudek, F. E. (1991) Intracellular electrophysiological study of suprachiasmatic nucleus neurons in rodents: excitatory synaptic mechanisms. J. Physiol. (Lond.), 444, 269-287.

König, H., Ponta, H., Rahmsdorf, H. J. and Herrlich, P. (1992) Interference between pathway-specific transcription factors; glucocorticoids antagonize phorbol ester-induced AP-1 activity without altering AP-1 occupation in vivo. EMBO J., 11, 2241-2246.

Kornhauser, J. M., Nelson, D. E., Mayo, K. E. and Takahashi, J. S. (1990) Photic and circadian regulation of $c$-fos gene expression in the hamster suprachiasmatic nucleus. Neuron, 5, 127-134.

Kornhauser, J. M., Nelson, D. E., Mayo, K. E. and Takahashi, J. S. (1992) Regulation of jun-B messenger RNA and AP-1 activity by light and a circadian clock. Science, 255, 1581-1584.

Kovary, K. and Bravo, R. (1991) Expression of different JUN and FOS proteins during the G0 to $\mathrm{G} 1$ transition in mouse fibroblasts: in vitro and in vivo associations. Mol. Cell. Biol., 11, 2451-2459.

Kovary, K. and Bravo, R. (1992) Existence of different Fos/Jun complexes during the G0-to-G1 transition and during exponential growth in mouse fibroblasts: differential role of Fos proteins. Mol. Cell. Biol., 12, 5015-5023

Masquilier, D. and Sassone-Corsi, P. (1992) Transcriptional cross-talk: nuclear factors CREM and CREB bind to AP- 1 sites and inhibit activation by Jun. J. Biol. Chem., 267, 22460-22466.

Mead, S., Ebling, F. J. P., Maywood, E. S., Humby, T., Herbert, J. and Hastings, M. H. (1992) A nonphotic stimulus causes instantaneous phase advances of the light-entrainable circadian oscillator of the Syrian hamster but does not induce the expression of c-fos in the suprachiasmatic nuclei. J. Neurosci, 12, 2516-2522.

Möller, C., Bing, O. and Heilig, M. (1994) c-Fos expression in the amygdala: in vivo antisense modulation and role in anxiety. Cell. Mol. Neurobiol., in press.

Morgan, J. I. and Curran, T. (1991) Stimulus-transcription coupling in the nervous system: involvement of the inducible proto-oncogenes fos and jun. Annu. Rev. Neurosci., 14, 421-451.

Neckers, L., Whitesell, L., Rosolen, A. and Geselowitz, D. A. (1992) Antisense inhibition of oncogene expression. Crit. Rev. Oncogen., 3, 175-231.

Nishikura, K. and Murray, J. M. (1987) Antisense DNA of proto-oncogene 
c-fos blocks renewed growth of quiescent 3T3 cells. Mol. Cell. Biol., 7, 639-649.

Perez, J., Li, Y., Stein, C. A., Majumder, S., van Oorschot, A. and Narayanan, R. (1994) Sequence-independent induction of Sp-I transcription factor activity by phosphorothioate oligodeoxynucleotides. Proc. Natl Acad. Sci. USA, in press.

Pfarr, C. M., Mechta, F., Spyrou, G., Lallemand, D., Carillo, S. and Yaniv, M. (1994) Mouse JunD negatively regulates fibroblast growth and antagonizes transformation by ras. Cell, 76, 747-760.

Rauscher, F. J., III, Sambucetti, L. C., Curran, T., Distel, R. J. and Spiegelman, B. M. (1988) Common DNA binding site for Fos protein complexes and transcription factor AP-1. Cell, 52, 471-480.

Rea, M. A. (1989) Light increases fos-related protein immunoreactivity in the rat suprachiasmatic nuclei. Brain Res. Bull., 23, 577-581.

Rusak, B., Robertson, H. A., Wisden, W. and Hunt, S. P. (1990) Light pulses that shift rhythms induce gene expression in the suprachiasmatic nucleus. Science, 248, 1237-1240

Rusak, B., McNaughton, L., Robertson, H. A. and Hunt, S. P. (1992) Circadian variation in photic regulation of immediate-early gene mRNAs in rat suprachiasmatic nucleus cells. Mol. Brain Res., 14, 124-130.

Ryseck, P. and Bravo, R. (1991) c-JUN, JUN B, and JUN D differ in their binding affinities to AP-I and CRE consensus sequences: effect of FOS proteins. Oncogene, 6, 533-542.

Ryseck, R., Hirai, S., Yaniv, M. and Bravo, R. (1987) Transcriptional activation of c-jun during the $\mathrm{G} 0 / \mathrm{Gl}$ transition in mouse fibroblasts. Nature, 334, 535-537.

Saffen, D. W., Cole, A. J., Worley, P. F., Christy, B. A., Ryder, K. and Baraban, J. M. (1988) Convulsant-induced increase in transcription factor messenger RNAs in rat brain. Proc. Natl Acad. Sci. USA, 85, 7795-7799.

Schlingensiepen, K. H. and Brysch, W. (1992) Phosphorothioate oligomers: inhibitor of oncogene expression in tumor cells and tools of gene function analysis. In Erickson, R. and Izant, J. (eds), Gene Regulation: Biology of Antisense RNA and DNA. Raven Press, New York, pp. 317-328.

Schlingensiepen, K. H., Schlingensiepen, R., Kunst, M., Klinger, I., Gerdes, W., Seifert, W. and Brysch, W. (1993) Opposite functions of Jun-B and cJun in growth regulation and neuronal differentiation. Dev. Genet., 14, 305-312.
Schlingensiepen, K. H., Kunst, M., Gerdes, W. and Brysch, W. (1994) Complementary expression patterns of $c$-jun and jun-B in rat brain and analysis of their function with antisense oligonucleotides. In Tölle, $T$. and Zieglgänsberger, W. (eds), Immediate Early Genes: More Than Activity Markers. Springer-Verlag, Berlin, in press.

Sonnenberg, J. L., Macgregor-Leon, P. F., Curran, T. and Morgan, J. I. (1989) Dynamic alterations occur in the levels and composition of transcription factor AP-1 complexes after seizure. Neuron, 3, 359-365.

Sutin, E. L. and Kilduff, T. D. (1992) Circadian and light-induced expression of immediate early gene mRNAs in the rat suprachiasmatic nucleus. Mol. Brain Res., 15, 281-290.

Takahashi, J. S. (1993) Circadian-clock regulation of gene expression. Curr. Opin. Genet. Dev., 3, 301-309.

Takahashi, J. S. and Turek, F. W. (1987) Anisomycin, an inhibitor of protein synthesis, perturbs the phase of a mammalian circadian pacemaker. Brain Res., 405, 199-203.

Vindlacheruvu, R. R., Ebling, F. J. P., Maywood, E. S. and Hastings, M. H. (1992) Blockade of glutamatergic neurotransmission in the suprachiasmatic nucleus prevents cellular and behavioural responses of the circadian system to light. Eur. J. Neurosci., 4, 673-679.

Wang, Z. Q., Ovitt, C., Grigoriadis, A. E., Möhle-Steinlein, U., Rüther, U. and Wagner, E. F. (1992) Bone and haematopoietic defects in mice lacking c-fos. Nature, 360, 741-745.

Wisden, W., Errington, M. L., Williams, S., Dunnett, S. B., Waters, C., Hitchcock, D., Evan, G., Bliss, T. V. and Hunt, S. P. (1990) Differential expression of immediate early genes in the hippocampus and spinal cord. Neuron, 4, 603-614.

Wollnik, F. (1991) Strain differences in the pattern and intensity of wheel running activity in laboratory rats. Experientia, 47, 593-598.

Wollnik, F. (1992) Neural control of circadian rhythms in mammals. Verh. Disch. Zool. Ges., 85, 231-246.

Wollnik, F., Turek, F. W., Majewski, P. and Takahashi, J. S. (1989) Phase shifting the circadian clock with cycloheximide: response of hamster with an intact or split rhythm of locomotor activity. Brain Res., 496, 82-88.

Zhang, X. K., Wills, K. N., Husmann, M., Hermann, T. and Pfahl, M. (1991) Novel pathway for thyroid hormone receptor action through interaction with jun and fos oncogene activities. Mol. Cell. Biol., 11, 6016-6025. 